\title{
The Politics of Children's Internet Use
}

Victoria Nash

\section{Understanding Children's Internet Use}

\section{THE DANGEROUS MYTH OF THE DIGITAL NATIVE}

From inspection of daily newspaper headlines it could plausibly be assumed that the Internet's main impact on the lives of children has been the deplorable pollution and corruption of impressionable young minds. ${ }^{1}$ Clearly this is a very one-sided view. Whilst each headline depicts a legitimate news story in which the well-being of youngsters is at risk, they tell us far more about the media's traditional dependence on bad rather than good news, and, perhaps more interestingly, about public appetite for scare-stories concerning the Internet and its implied risks for children.

One factor which helps to explain some of the moral panic surrounding children's Internet use is the simple point that children are often presumed to be more expert users than either their parents or law-makers. Characterized by Prensky (2001) as the difference between "digital natives" (those who have grown up with the technology) and "digital immigrants" (those who come to it later in life), this makes an assumption that all children born in the digital era are equally adept at using technology, even displaying the capacity to "think and process information fundamentally differently from their predecessors" (p. 1). Unfortunately, this bluntly essentialist dichotomy is damaging on two fronts. First it encourages us to think that it's impossible for the older generation to understand or keep pace with children's Internet use, and second, it manages to obscure many policy-relevant variations in Internet use and access between children. In reality, the picture is, of course far more nuanced. Children growing up in Western nations increasingly enjoy near-universal access to the Internet, at least in school, but there remain considerable

${ }^{1}$ For the purposes of this chapter, the term "child" will be taken to refer to any person under the age of eighteen, using the same definition as the United Nations for the purposes of the Convention on the Rights of the Child. Where the research described in the text refers only to a particular subset of this age-group, this will be specified. 
differences and inequalities in the extent and types of use, whilst some adults share many of the characteristics of supposed "digital natives" in their Internet use (Helsper and Eynon 2010).

The range of influences shaping children's Internet access and use include both internal and external factors. Most obviously, each child brings a different range of skills to their online activities. Necessary skills include basic motor and technical skills, more specific Internet-related abilities such as search techniques, as well as generic skills such as information literacy and emotional intelligence. Unsurprisingly, the wider the child's range of skills, the more variety in their use of their Internet and the more likely they are to benefit from it (Livingstone and Helsper 2010). Self-efficacy, or self-confidence, is also important in explaining differences in children's capacity to take up online opportunities (Eynon and Malmberg 2011).

Amongst the most important external factors that shape children's Internet use are the availability of home access and levels of support. Home (rather than school) access has been shown to affect both the depth and range of online activities undertaken (Facer et al. 2003). Although households with children are much more likely to have Internet access than those without (Eurostat 2010; Dutton and Blank 2011), there are still significant numbers of children who don't enjoy such access, for example the 7 percent of UK twelveto fifteen-year-olds lacking desktop or laptop use at home (Ofcom 2011). Unsurprisingly, those in the lowest socio-economic groups are most likely to lack home access (Ofcom 2011). In terms of support, it's not just a question of how much, but also from whom and what type. Support from those with positive Internet experience is more valuable in building children's online confidence (Eastin 2005 cited in Davies and Eynon 2012), whilst children whose parents lack confidence about Internet use may come to rely more heavily on peer support, with fewer opportunities for parents to pass on social norms (Palfrey and Gasser 2008) or provide emotional back-up (Ito et al. 2010; Turkle 2011). Building on these findings about the importance of social support we can see that the "digital natives" myth is damaging in a third sense, insofar as its frequent repetition actually risks undermining parents' and educators' confidence in their own ability to provide positive support to the young Internet users in their charge.

Understanding the variability of children's Internet experiences is vital for policy purposes, both because such inequality in access and use may constitute an important injustice, and also because the differences mean that not all children face the same combination of risks and opportunities. In both cases, policy responses that treat all children as equally confident and skilled "digital natives" will be fundamentally inadequate, so policy, parenting, and educational strategies should be adjusted accordingly. The sections below will consider in more detail how this variability plays out in two specific contexts: for educational purposes, and in children's embrace of it in their private lives. 


\section{Hopes and Expectations: Internet Use and Education}

Despite the fore-mentioned media focus on the Internet's dark side, technology policy has also been driven by optimistic (and potentially vote-winning) strategies to achieve beneficial social outcomes. Information and communication technologies have long been seen to offer many valuable opportunities for children, potentially delivering educational benefits such as improved learning outcomes and skills important for workforce participation, and also more personal benefits such as enhanced self-esteem or self-efficacy (Davies and Eynon 2012). These expectations are often visible in the political rhetoric surrounding the launch of new investment programs, albeit frequently colored by a naive technological determinism that drives a fascination with investment in hardware rather than people (Livingstone 2009).

Whatever the rhetoric, governments across most Western nations have invested significant resources in wiring up schools since 2000, and in many cases such programs have played an important role in expanding national broadband infrastructure. Even though this is clearly a positive development, it doesn't mean that all pupils enjoy similar levels of resource, skills, or support. To start with, not all pupils seem to actually use the Internet at school: the EU Kids Online pan-European survey reported that just two-thirds of pupils claim to do so (Livingstone et al. 2011). Even for those children who do go online at school, the quality of experience may vary dramatically, depending on factors such as teachers' proficiency in integrating Internet use into class work or the level of support provided to help children work effectively. The inequity of these conditions is further exacerbated by the fact that schools from richer and poorer areas often face very different educational challenges which technology use in the classroom cannot be expected to overcome (Warschauer et al. 2004).

A further reason to be wary of the grand claims made for the role of the Internet in transforming children's education comes from the constrained nature of its use in schools. Teachers are necessarily limited by pedagogical requirements to cover certain curricula, which in the $\mathrm{UK}$, for example, means that children are more likely to learn word processing than programming (Birmingham and Davies 2005). They are also charged with ensuring safe and appropriate behavior, such that school Internet use is usually filtered and even surveilled (Buckingham 2007). Both constraints mean that youngsters using the Internet at school are likely to face a more limited set of opportunities in terms of what sites or information they can access, albeit also a reduced array of risks. So long as a sizeable number of pupils continue to lack access to the Internet at home-what Buckingham (2007) has called the "digital divide between in-school and out-of-school use"-the restrictions and inequities of Internet use in school will continue to have discriminatory effects. 
Unfortunately, expectations of the Internet's improving effect on formal educational outcomes have yet to be fulfilled, with research suggesting neither any obvious positive or negative impact (Livingstone 2009). Nor does it seem to be the case that the Internet's collaborative and creative potential is exploited to the full for academic purposes. As Davies and Eynon note: "the Internet serves most of all as a reassuring quick fix for teenage learners" (Davies and Eynon 2012: 88), providing opportunities to consult, in the preparation of assignments, a variety of information sources whether they be Google, Wikipedia, or friends.

It has been suggested that such a focus on formal educational outcomes is misplaced. An influential study for the MacArthur Foundation argued that teenage Internet users are increasingly engaged in a "participatory culture," namely, "a culture with relatively low barriers to artistic expression and civic engagement, strong support for creating and sharing one's creations and some type of informal mentorship whereby what is known by the most experienced is passed along to novices" (Jenkins et al. 2006: 3). As the next section will make clear, many of the skills required to engage in such a culture may be better learnt through "informal learning" outside schools, meaning (rather ironically) that personal, private Internet use at home which gives rise to so many parenting fears may ultimately be best placed to build the soft skills required in Internet-enabled cultures.

\section{Personal Internet Use: Risk or Opportunity?}

Many aspects of children's personal lives are mediated by the Internet. It offers valued platforms for creating and playing with identities, making and talking to friends, even for living out some of the most mundane aspects of family life. It's not so much that these activities are new in themselves, but rather that children and teenagers "are doing this while the contexts for communication, friendship, play, and self-expression are being reconfigured through their engagement with new media" (Ito et al. 2010: 1). Such reconfiguration is itself helping to re-shape existing practice, such as where traditional efforts by teenagers to change their appearance and image give way to the conscious creation and curation of online identities, as well as the revision of existing norms (for example, around the use and re-use of third-party created content). As these altered practices and norms play out, the array of risks and opportunities facing children is also transformed, and it's no surprise that many media-driven outpourings of moral panic concern supposed horrors resulting from children's determination to connect with others online. For many parents and policy makers, perhaps the greatest source of anxiety is the extent to which children and teenagers can conduct much of their personal life online, in an 
environment which is perversely private in the sense that a responsible adult can easily be excluded, but public insofar as the content or communication is effortlessly opened up to unknown others.

According to the EU Kids Online Survey, 60 percent of European nineto sixteen-year-olds go online almost daily, with an average duration of just under an hour and a half for all nine- to sixteen-year-olds, and more than three hours a day for those aged fifteen to sixteen (Livingstone et al. 2011). Despite the emphasis placed on Internet use in schools, the most common point of access is still home rather than school and increasingly, in the private spaces of the bedroom or using a personal device such as a laptop or a mobile (Livingstone et al. 2011). Apart from schoolwork, the most common uses of the Internet amongst this group are for entertainment and socializing, such as playing online games, watching videos, and using Instant Messenger (IM), email, or social networks to communicate with friends (Livingstone et al. 2011). Although some children are indeed engaged in what Jenkins describes as "participatory cultures" (Jenkins et al. 2006), perhaps blogging or posting content for others to share, these activities are undertaken by relatively few, supporting the concept of a "ladder of opportunities" which children may ascend at different rates and to different levels (Livingstone et al. 2011; Livingstone and Helsper 2007). Ito et al. (2010) note that for most teenagers, creativity is mainly expressed in "everyday personal media production" as they document their daily lives through social media, but that for some, this does become a "jumping-off point" for more elaborate forms of creativity (p. 290). And whilst these more creative activities (photography, blogging, music or video production, etc.) may initially be interest-driven, they can develop into intensely social activities, generating their own communities of interest and becoming important forms of self-expression, the latter being a particularly important feature of Internet use for older children and teenagers.

Starting from the premise that identity is not fixed and objective, but fluid and mutable, the Internet enables the "performance" of identity across a range of sites and for different audiences, albeit with imperfectly permeable boundaries (boyd 2007; boyd and Marwick 2011). Although identity performance takes place across a range of platforms including IM, chat rooms and texting, the rise of social network sites (SNSs), with their central focus on a self-constructed personal profile, has provided a natural home for such activity. While social network sites such as Facebook are currently for use only by those over thirteen, 59 percent of European children between nine and sixteen claim to have a social networking profile, with age-specific practices varying from 26 percent for those aged nine-ten to 82 percent for those at the top of the age range (Livingstone et al. 2011). In the United States, 80 percent of online teenagers between twelve and seventeen use social networks, far more than the 64 percent of online adults using such services (Lenhart et al. 2011). Whilst the use of SNSs for social and expressive purposes is not necessarily 
problematic, these figures do raise legitimate policy concerns, implying that large numbers of children are using sites not designed for their age group, and potentially without parental consent or knowledge.

Perhaps unsurprisingly in this context, privacy is a concern for both young SNS users and their parents. Although some studies suggest that young SNS users are discriminating in their choice of which personal information to publicize (Patchin and Hinduja 2010), others note that the architecture of such sites can raise particular problems for teens, whose subtle groupings and rankings of offline friends are poorly served by the blunt categorization of "friends" on SNSs, making the practice of privacy in SNSs much harder to negotiate. In one study, teenagers speak of their frustration in trying to signal whom particular content is directed towards, and of how they seek to erect artificial boundaries to separate parts of their networks (boyd and Marwick 2011). Just because material on SNSs is public in the sense that it is accessible to friends (and often friends of friends or the wider world) does not mean that young users want all of their network to access it, especially when that network may include parents or relatives.

Whilst children and teenagers may be in thrall to the potential of SNS to help them curate their online identities, they are also reliant on them for communication. This ability to master the affordances of particular platforms or technologies and make them work for a particular end, in this case establishing or maintaining friendships, is a skill which many, particularly older children and teens, manifest. Many studies note how young Internet users seamlessly manage a portfolio of different communication tools to sustain their social and family relationships, such as IM, Facebook, messaging, and texting for quick and intimate conversations, social network status updates to check in with a broader group, or mobile phone calls for private and urgent conversations (Ito et al. 2010; Livingstone 2009; Davies and Eynon 2012). Although some have raised concerns about the burden of managing so many different modes of communication (Turkle 2011), and the strains of managing complex social hierarchies with relatively unsophisticated tools (Ito et al. 2010), the majority of the evidence suggests that Internet technologies play a key role for children and young people in expressing their developing and mutable social selves.

\section{Internet Regulation: Protecting or Politicizing Children?}

In contrast to the panic-laden news headlines that have accompanied children's adoption of the Internet, the more positive aspects of Internet use rarely receive the same media coverage or policy recognition as the risks. This isn't to say that concern for such risks is illegitimate: clearly, states, parents, and 
educators have a duty to protect. Rather, there are two problems with such a one-sided approach: first, there is a tendency to ignore messy details, such as the fact that some children are more vulnerable than others or that harm is hard to detect, and second, it ignores the possibility that risk and opportunity may go hand in hand.

\section{RISK AND HARM}

Whilst there is a rich and expanding body of literature investigating how children's Internet use shapes their experience of risks and opportunities, there are still some real weaknesses. From a policy perspective, one of the biggest problems is that we know relatively little about the relationship between risk and actual harm, or the way in which different risk factors combine to increase or decrease risks for particular children. Most fundamentally, there are real methodological and ethical challenges involved in measuring harms to children resulting from Internet use; so many studies in this area measure not harm, or even risk, but the "risk of risk" (Livingstone 2010: 4), for example, the likelihood that any one child will access pornography, rather than the likelihood that he/she will be harmed by this experience. This poses a problem for responsible evidence-based policy making, meaning that even with the best of intentions, policies are likely to be constructed on the basis of judgments about the potential risk of Internet use.

Despite this limitation, there are many excellent studies investigating the range of risks that children are exposed to online. The risks most frequently encountered by children online are exposure to pornographic content and bullying, although there is a surprising degree of variation in prevalence between studies. For example, in the United States, Wolak, Mitchell, and Finkelhor's representative sample survey (2007) show that 42 percent of American tento twelve-year-olds have been exposed to online pornography in the past year-66 percent of which was unwanted exposure, whilst the EU Kids Online Project reports that 14 percent of Europe's nine- to sixteen-year-olds have been exposed to sexual images online. Cyber-bullying has proved particularly hard to measure with prevalence figures for the United States ranging from 9 percent (Ybarra et al. 2006) to an amazing 72 percent (Juvenon and Gross 2008). Although there is no single factor that can explain the huge variation in results, this is likely to result from differences in the studies' operationalization of key concepts such as "cyber-bullying," as well as different survey methods and sampling strategies.

At the other end of the scale one of the most feared online risks-sexual predation by a stranger-appears to be very rare, although the seriousness of this offence means that despite the low number of occurrences it understandably merits extensive policy attention. A lesser variant, online sexual solicitation and receipt of sexual messages (often from acquaintances) is more common, especially for 
girls, with between 15 and 19 percent reporting such experiences (Baumgartner et al. 2010; Livingstone et al. 2011). Although this figure sounds very alarming, it is worth noting that sexual conversations between teenagers are not necessarily a source of concern, indeed, the majority of children do not report being upset or bothered by this, and many take active steps to prevent a recurrence (Livingstone et al. 2011). With the advent of "sexting", ${ }^{2}$ however, the potential harms associated with peer-produced content (rather than "stranger-danger") most certainly merit further attention from both researchers and policy makers.

In addition to these long-acknowledged risks, the Internet's capacity to cater for more specialist audiences has seen the rise of online sites and communities exchanging information and advice on issues such as anorexia, bulimia, self-harm, and suicide. Whilst there is little disagreement in the academic literature as to the potential harm of such sites, there is uncertainty about the balance between the dangers of normalizing damaging behavior, and the value for vulnerable youngsters of finding a non-judgmental space to discuss personal problems with similar others. There is also as yet little research which shows that otherwise healthy children or teenagers are at risk from such content; indeed, many studies in this field show that children who are vulnerable offline are more likely to be susceptible to online risks and harms. Acknowledged predictors of exposure to pornography, self-harm material or other online risks include depression, sexual abuse, eating disorders, or risk-seeking behavior offline (Wolak et al. 2007; Mitchell and Ybarra 2007). Such children may be doubly at risk in the sense that they also lack resources or "resilience" to cope with online risks and may also be less likely to seek support from family or other responsible adults. This poses particular challenges for policy, suggesting a need to more effectively target resources at vulnerable groups.

Counter-intuitively though, other studies have revealed that greater opportunities of use also go hand in hand with greater exposure to online risk, meaning that older, more sophisticated users, or those from middle-class households who enjoy better access also encounter more risk (Livingstone 2009). These findings suggest that policy makers seeking to reduce exposure to online risks need to find ways of supporting children who are most vulnerable on other measures, as well as those who are privileged and confident Internet users-potentially two very different groups.

\section{Policy Responses-Serving our Children Well?}

As noted earlier, media and policy pre-occupation with the negative aspects of children's Internet use is problematic if this results in policy outcomes which

\footnotetext{
2 "Sexting" is the exchange of sexually explicit images or messages via mobile phone.
} 
restrict opportunities at the same time as reducing risks. In the context of communication technologies this is a particular concern, as many available policy tools offer protection only by reducing opportunities for the free exchange of information or speech. The importance of balancing these competing goals is recognized in legal or constitutional protections in many countries and in international instruments such as the United Nations Convention on the Rights of the Child. ${ }^{3}$

Against this backdrop we should question whether policies relating to children's use of the Internet generally do strike the right balance between the protection of well-being and protection of free speech. It is worth noting at the outset that our concern here is online activities which may pose risks for children rather than those which illegally harm children (such as creation or circulation of child-abuse images). It is often argued that in a situation of such uncertainty it's better to employ precautionary principles to minimize the occurrence of possible harms, particularly when seeking to protect potentially vulnerable individuals (Livingstone 2010). It should also be acknowledged that whilst research evidence may be scarce, there are many other factors (moral, cultural, religious, economic, etc.) that can legitimate policy intervention. But it shouldn't be forgotten that there are also some very poor reasons for policy intervention, such as the "symbolism" of being seen to do something even if that "something" fails to ameliorate the original policy problem (Heins 2001; Sandvig 2001).

A standard policy response to many of the risks outlined in this chapter, for example, is that certain sorts of web content deemed potentially harmful to children should be blocked or filtered, a child-protection solution with a long history in other media (Heins 2001). ${ }^{4}$ Filtering methods can be applied at different "choke points" across the Internet ranging from state-directed filtering schemes where blocking is carried out at backbone level, to filtering by search engines or Internet Service Providers (ISPs), all the way down to filtering at the level of the household or institution. Although advocates of free speech argue that filtering decisions should be made as close as possible to the individual user, several countries, including Denmark, South Korea, and the United States have introduced legislation requiring publicly funded schools and libraries to install filtering software to protect children using their facilities. Other countries, such as Australia and the UK, have held lengthy public debates concerning whether ISPs should be mandated to block pornographic content by default.

The introduction of such mandatory filters may seem to be a positive step towards reducing access to adult materials by young children but it remains a

\footnotetext{
${ }^{3}$ Available at <http://www2.ohchr.org/english/law/crc.htm> (accessed 20 August 2012).

${ }^{4}$ Discussion of filtering and blocking in this chapter refers only to material deemed potentially harmful and not to that which is illegal, such as child-abuse images or hate speech.
} 
controversial policy, both because it restricts access to otherwise legal content, often for adults as well as children, but also because no filter is ever 100 percent effective, either over-blocking legitimate content or under-blocking undesirable content. Over-blocking is particularly problematic if the material has educational or informational value, such as that pertaining to relationships, sexual health, or even art. There is also a danger that when filtering mechanisms are in place, parents or educators may be lulled into a false sense of security, believing that no further risks exist. Unfortunately, calls for mandatory filtering are politically attractive as they articulate a decisive policy response, and are more clearly understood by both the media and the public than subtle calls for improved digital literacy training or more effective parental interventions. A more moderate approach is the introduction of "active choice" policies such as those being introduced in the UK, whereby households signing up to new broadband contracts are asked whether they wish to have filters installed at the household level. This is a positive step insofar as it places the decision with parents, but even so it remains a rather blunt tool that cannot distinguish between the differing degrees of protection needed for various members of the household.

If we are to question whether filtering policies effectively protect children from significant risk or harm without undue damage to their rights to freedom of expression and information, we must also ask whether access policies do enough to support equal rights. Although sections of this chapter noted the near-universal efforts in Western developed countries to get schools online, there are still significant inequalities of provision, and children lacking home access remain at a disadvantage. To this extent, policies such as the UK's now-defunct Home Access Programme, which sought to provide laptops for low-income families, could make a great contribution to equalizing opportunities, but are as yet all too rare. In the absence of wide-scale investment in home access, it is vital that better support is provided for school implementation of Internet-supported learning, including teacher training and curriculum development; just as importantly though, it would be highly beneficial if after-school and holiday provision could find ways of making Internet access available in ways that better mimic home use.

To a large degree, policy debates around children's Internet use have long been dominated by concerns about harmful content and access, but other newer policy issues are emerging rapidly, and to do justice to the next generation of Internet users these must be given more consideration. With the current array of tools for creation, use, re-use, and sharing of content, concerns about children's respect for intellectual property and copyright laws have gained new importance. As noted above, the most sophisticated forms of content creation are only engaged in by a minority of children, but large numbers are enjoying simpler uses, such as portraying their everyday lives and relationships through the crafting of SNS profiles or photo-sharing. However, many 
of the most exciting new opportunities for digital creativity leave children "at risk for ongoing copyright liability" (Palfrey and Gasser 2008: 117). Given that there have already been several high-profile cases of under-18s being pursued by property-owners for abuse of copyright, this risk is all too real. Although it's clearly unrealistic to expect intellectual property regimes to change overnight, there is a bifurcated danger, either that the creative potential of today's most digitally literate children will be stifled, or that their online norms and practices will simply further depart from the current state of the law. Both would seem undesirable.

Children's online practices are similarly ill served by privacylaws (Matwyshyn 2012). At risk both of personal damage that can result from context collapse, as when parents or future employers obtain information from public SNS pages, and also corporate misuse of their data, this is another area where current norms and practice by under-18s do not fit neatly within existing frameworks of legal protection. Whilst there have been efforts to introduce legislation to address the specific needs of those too young to contract on their own behalf, such as the US Children's Online Privacy Protection Act 1998 (COPPA) or the EU's proposed revisions to the Data Protection Directive, in practice this has just meant that popular services such as Facebook apply a minimum age limit of thirteen, but lack effective means of policing this, leaving young users with little protection. Although the proposed EU "right to forget" reinforces privacy policy in ways that might help those who post vigorously in their youth but seek more anonymity later on, it is hard to imagine a straightforward solution (Millard, chapter 21 this volume).

\section{Conclusion}

For many, there could be no better illustration of the "dark side of the Internet" than the media's hysterical portrayal of children's daily exposure to paedophiles, pornography, and gambling. Yet, although such risks undoubtedly do exist and merit serious-minded attention from policy makers, the moral panic surrounding their prevalence serves to obscure another dark corner in this debate, namely the misrepresentation of children in Internet policy and regulation, and the tendency to favor policy measures that restrict, rather than expand, access to information and speech. This chapter has sought to clarify how purported concern for the well-being of our children and teenagers is shaping the future of the Internet. Although there's certainly nobility in such concern, it's unfortunately not obvious that children's interests are necessarily well served by the dominant trends in Internet policy which seem to promote protection but not empowerment (Lunt and Livingstone 2012). 
First, too much emphasis is placed on reducing some of the most feared (but not necessarily most harmful) risks by introducing technical fixes such as filtering, rather than engaging with the messy realities of parenting, education, and child development. Second, there is little acceptance of children's rights to freedom of expression and information, too often regarded as less important than their rights to protection from harm, even when that harm is uncertain or unlikely. Such an imbalance may be partly understood as a result of a general failure to accept that childhood is itself a socially defined construct, and that media portrayal of children as helpless, vulnerable victims of online harms is outdated at a juncture where youngsters are capable of both perpetrating online abuse and helping to protect themselves against it. Third, more effort must be made to support positive use or help those who are most vulnerable rather than the easy-to-reach middle-classes' children with anxious parents. Finally, and perhaps more importantly, there needs to be a wider recognition that no one is well served if genuine concerns for child protection are manipulated and misused in the pursuit of other less noble political goals, such as the quiet pursuit of moral conservatism and social control. Many of those who oppose heavy-handed content filtering might be more easily appeased if significant policy resources were also devoted to promoting access and positive Internet use, underscoring a genuine political commitment to supporting children's well-being. The Internet, quite simply, poses both risks and opportunities for young users, and a serious-minded policy approach should embrace the resulting trade-offs and complexities.

\section{REFERENCES}

Baumgartner, S., Valkenburg, P., and Peter, J. (2010). "Unwanted Online Sexual Solicitation and Risky Sexual Online Behavior Across the Lifespan," Journal of Applied Developmental Psychology, 31(6): 439-447.

Birmingham, P. and Davies, C. (2005). "Implementing Broadband Internet in the Classroom: Key Issues for Research and Practice." Oxford Internet Institute Research Report No. 6, University of Oxford. <http://www.oii.ox.ac.uk/resources/publications/RR6.pdf> (accessed January 22, 2012).

boyd, d. (2007). "Why Youth (Heart) Social Network Sites: The Role of Networked Publics in Teenage Social Life," in D. Buckingham (ed.), Youth Identity and Digital Media Cambridge, MA: MIT Press, 119-142.

boyd, d. and Marwick, A. (2011). "Social Privacy in Networked Publics: Teens' Attitudes, Practices and Strategies" (paper presented at the Oxford Internet Institute conference "A Decade in Internet Time," September 22, 2001). <http://papers.ssrn.com/sol3/papers.cfm?abstract_ id=1925128> (accessed August 15, 2012).

Buckingham, D. (2007). The Impact of the Media on Children and Young People with a Particular Focus on Computer Games and the Internet (Annex G of the Byron Review). <www.lloydminster.info/libdocs/byronreview/annex_g.pdf> (accessed August 28, 2012).

Davies, C. and Eynon, R. (2012). Teenagers and Technology. New York: Routledge. 
Dutton, W. H. D. and Blank, G. (2011). Next Generation Users: The Internet in Britain 2011. Oxford: Oxford Internet Institute, University of Oxford. <http://www.oii.ox.ac.uk/publications/oxis2011_report.pdf> (accessed 14 January 2013.

Eastin, M. (2005). “Teen Internet Use: Relating Social Perceptions and Cognitive Models to Behavior," Cyberpsychology and Behavior, 8(1): 62-75.

Eurostat (2010). “Internet Access and Use in 2010," Eurostat News Release. <http://epp.eurostat. ec.europa.eu/cache/ITY_PUBLIC/4-14122010-BP/EN/4-14122010-BP-EN.PDF> (accessed August 6, 2012).

Eynon, R. and Malmberg L. (2011). "Understanding the Online Information Seeking Behaviours of Young People: The Role of Networks of Support," Journal of Computer Assisted Learning, 28(6): 514-529.

Facer, K., Furlong, J., Furlong, R., and Sutherland, R. (2003). Screenplay: Children and Computing in the Home. London: Routledge Falmer.

Helsper, E. J. and Eynon, R. (2010). “Digital Natives: Where is the Evidence?” British Educational Research Journal, 36(3): 503-520.

Heins, M. (2001). Not in Front of the Children. New York: Hill and Wang.

Ito, M., Baumer, S., Bittanti, M., boyd, d., Cody, R., Herr-Stephenson, B., Horst, H., Lange, P. G., Mahendran, D., Martinez, K., Pascoe, C. J., Perkel, D., Robinson, L., Sims, C. and Tripp, L. (2010). Hanging Out, Messing Around, and Geeking Out. Cambridge, MA: MIT Press.

Jenkins, H., Clinton, K., Purushotma, R., Robison A. J., and Weigel, M. (2006). Confronting the Challenges of Participatory Culture: Media Education for the 21st Century. The MacArthur Foundation. Cambridge, MA: MIT Press.

Lenhart, A., Madden, M., Smith, A., Purcell, K., Zickuhr, K., and Rainie, L. (2011). “Teens, Kindness and Cruelty on Social Network Sites," Pew Internet and American Life Project. Online. <http:// pewinternet.org/ /media//Files/Reports/2011/PIP_Teens_Kindness_Cruelty_SNS_Report_ Nov_2011_FINAL_110711.pdf> (accessed August 15, 2012).

Livingstone, S. (2009). Children and the Internet. Cambridge: Polity Press.

Livingstone, S. (2010). “e-Youth: (Future) Policy Implications: Reflections on Online Risk, Harm and Vulnerability" (paper presented at e-Youth: Balancing Between Opportunities and Risks, 27-28 May 2010, UCSIA and MIOS University of Antwerp, Antwerp, Belgium, < $<$ http:// eprints.lse.ac.uk/27849/> (accessed August 28, 2012.

Livingstone, S., Haddon, L., Görzig, A., and Ólafsson, K. (2011). Risks and Safety on the Internet: The Perspective of European Children. Full Findings. London: EU Kids Online, LSE.

Livingstone, S. and Helsper, E. J. (2007). "Gradations in Digital Inclusion: Children, Young People and the Digital Divide," New Media and Society, 9(4): 671-696.

Livingstone, S. and Helsper, E.J. (2010) "Balancing Opportunities and Risks in Teenagers' Use of the Internet: The Role of Online Skills and Internet Self-Efficacy," New Media \& Society, 12 (2): 309-329.

Lunt, P. and Livingstone, S. (2012). "Media Literacy." Chapter 6 in Media Regulation: Governance and the Interests of Citizens and Consumers. London: Sage.

Matwyshyn, A. (2012). "Generation C: Childhood, Code and Creativity" Notre Dame Law Review 87 (5): 1979-2030.

Mitchell, K. and Ybarra, M. (2007). "Online Behavior of Youth who Engage in Self-Harm Provides Clues for Preventive Intervention,” Preventive Medicine, 45(5): 392-396.

Ofcom (2011). UK Children's Media Literacy Report. London: Ofcom. <http://stakeholders.ofcom. org.uk/binaries/research/media-literacy/media-lit11/childrens.pdf $>$ (accessed August 28, 2012). 
Palfrey, J. and Gasser, U. (2008). Born Digital. New York: Basic Books

Patchin, J.W. and Hinduja, S. (2010). "Changes in Adolescent Social Networking Behaviours from 2006 to 2009," Computers in Human Behaviour, 26(6): 1818-1821.

Prensky, M. (2001). “Digital Natives, Digital Immigrants: Part 1,” On the Horizon, 9(5): 1-6.

Sandvig, C. (2001). "Unexpected Outcomes in Digital Divide Policy: What Children Really Do in the Public Library," in B. M. Compaine and S. Greenstein (eds), Communications Policy in Transition: The Internet and Beyond. Cambridge, MA: MIT Press, 265-293.

Turkle, S. (2011). Alone Together. New York: Basic Books.

Warschauer, M., Knobel, M., and Stone, L. (2004). "Technology and Equity in Schooling: Deconstructing the Digital Divide," Educational Policy, 18(4): 562-588.

Wolak, J., Mitchell, K., and Finkelhor, D. (2007). "Unwanted and Wanted Exposure to Online Pornography in a National Sample of Youth Internet Users," Pediatrics, 119(2): 247-257.

Ybarra, M., Mitchell, K., Wolak, J., and Finkelhor, D. (2006). "Examining Characteristics and Associated Distress Related to Internet Harassment: Findings from the Second Youth Internet Safety Survey," Pediatrics, 118(4): e1169-e1177. 